\title{
RELIABILITY OF TWO STAIN REMOVAL REGIMES ON COLOR CHANGE OF CONTEMPORARY RESIN-BASED RESTORATIVE MATERIALS IN VITRO STUDY
}

\author{
Y.M Hamouda*, H.Y. El Sayed*** and Th.M. Genaid**
}

\begin{abstract}
Objective: To evaluate the reliability of two methods of stain removal on the color change of a nanohybrid composite resin (N-Fill) and a resin-modified glass ionomer (Ionolux) after being subjected to a combined effect of staining by commonly consumed beverages.

Materials and methods: Twenty disk-shaped specimens were prepared from each of the two tested materials (N-Fill) and (Ionolux) representing groups (I) and (II) respectively. All specimens were stained individually in tea and cola solutions for 30 days. The stained specimens were divided randomly according to the method used for stain removal into equal groups of ten specimens each (IA), (IIA), (IB) and (IIB). Specimens in group (IA) and (IIA) were polished with Sof-Lex system, while those in group (IB) and (IIB) were bleached with Opalescence Boost $40 \%$ HP. VITA Easyshade spectrophotometer was used to measure the color of the specimens utilizing Commission international de l'éclairage $\mathrm{L}^{*} \mathrm{a} * \mathrm{~b} *$ color system. Measurements were performed four times: at baseline (original color), after staining, after polishing in group (IA) and (IIA) and after bleaching in group (IB) and (IIB). The color difference values $\left(\Delta \mathrm{E}^{*}\right)$ were calculated and statistically analyzed using One-way ANOVA and student t-tests at level of significance $(\mathrm{P} \leq 0.05)$.
\end{abstract}

Results: Staining resulted in a perceptible $\Delta \mathrm{E}^{*}$ values $(>3.3)$ in both materials. The recorded value (7.59) for Ionolux was beyond the clinically acceptable range (2.72-6.8) and was statistically significant different from that recorded for N-Fill (4.37). Polishing significantly affected color of $\mathrm{N}$-Fill $\left(\Delta \mathrm{E}^{*}=19.05\right)$ compared to Ionolux $\left(\Delta \mathrm{E}^{*}=10.07\right)$. While $\Delta \mathrm{E}^{*}$ values recorded after bleaching (19.64 and 15.7) were not statistically significant from each other.

Conclusions: The tested polishing and bleaching procedures utilized to remove stain from both tested materials resulted in a significant color change that was beyond the clinically accepted range.

KEYWORDS: Nanohybrid composite resin; Resin-modified glass ionomer; Staining; Color difference; Polishing; Bleaching

* Demonstrator of Conservative Dentistry Department, Faculty of Dentistry, Tanta University.

** Professor of Conservative Dentistry Department, Faculty of Dentistry, Tanta University. 


\section{INTRODUCTION}

Cosmetic dentistry is in its boom because of the increasing demand of the esthetic appraisal by the patients specially related to the stained dentition ${ }^{[1]}$ in addition to discoloration of esthetic restorations which was reported as one of the major concern which leads to their replacement.

As color is one of the most desirable properties of an esthetic restorative material, maintenance of the matched color for its entire service life may determine the success or failure of the material ${ }^{[2]}$. Therefore, the materials and techniques of esthetic dental procedures, such as resin-based restorative materials and bleaching techniques, are under constant development ${ }^{[3]}$.

Composite resins have become a popular material of choice, owing to their inherent property to emulate the natural color of teeth and the increasing demand amongst patients for esthetics ${ }^{[4]}$. The last few decades saw significant development of the material resulting in evolution of a multitude of contemporary composite resins ${ }^{[5]}$.

In addition, glass ionomer cements were introduced as a direct restorative material offering two unique advantages; release fluoride and chemical adherence to enamel and dentine. While resin-modified glass ionomers and compomers were developed later to overcome some of the disadvantages of conventional glass-ionomers specially the disability of maintenance adequate color stability ${ }^{[6,7]}$.

Discoloration can be caused by several intrinsic and extrinsic factors. Intrinsic factors involve the discoloration of the resin itself related to the alterations in the resin matrix and in the interface of filler and resin matrix. While, extrinsic factors discolor by adsorption or absorption from extrinsic sources ${ }^{[8]}$.

* MEGADENTA Dental Produkte GMBH GERMANY, ** VOCO GMBH, Cuxhaven GERMANY,
Under oral conditions, the esthetic restorations could be exposed to combined effects of light, moisture and oral habits which seem to produce a greater influence on the color of both the teeth and resin composite restorations ${ }^{[9]}$.

This highlights the needs for dental researchers and material scientists to improve the resistance of resin-based materials to discoloration ${ }^{[10]}$. In addition, different methods were attempted to remove the stain as brushing, polishing or bleaching procedures instead of restoration replacement ${ }^{[11]}$.

The removal of stain with tooth brushing is a slow process. Therefore, it is preferred to use more rapid methods, such as polishing or bleaching techniques. Polishing procedures, although remove material from the surface, can remedy highly stained restorations ${ }^{[12]}$.

Bleaching agents are generally based on hydrogen peroxide or carbamide peroxide and may be supplied in gel or liquid form. Both take-home and in-office bleaching techniques have proven effective results in teeth whitening with the latter having the advantage of producing immediate results ${ }^{[13,14]}$.

An adequate evaluation of color change in tooth restoration can be carried out either visually (using shade tabs), by colorimeter, or spectrophotometer, or by digital photo color assessments (with or without computer aided analysis) ${ }^{[15]}$.

The aim of this in vitro study was to evaluate the reliability of two methods of stain removal on the color change of a nano-hybrid composite resin and a resin modified glass ionomer after being subjected to a combined effect of tea and cola stain over a period of 30 days.

\section{MATERIALS AND METHODS}

N-Fill* (light curing methacrylate-based nanohybrid composite) and Ionolux ${ }^{* *}$ (light curing 
resin modified glass ionomer) restorative materials were used. The experimental design involved preparing of twenty disk-shaped specimens from each material representing two groups (I) and (II). All specimens were stained individually in two staining media (tea) and (cola) then were randomly divided according to the method of stain removal into equal groups (IA), (IIA), (IB) and (IIB) of 10 specimens each.

\section{Specimens preparation}

A circular rubber mold $(8 \mathrm{~mm}$ in diameter and $2 \mathrm{~mm}$ in thickness) was used for the specimen preparation, it was placed on white opaque background covered by a Mylar strip* and filled with materials under investigation. A second Mylar strip was placed on top of the filled mold and pressed flat with a glass slide to extrude the excess material producing specimens with smooth and flat surfaces. Specimens were light cured from both sides ${ }^{[16]}$ using a light-emitting diode curing unit ${ }^{* *}$ with a light intensity of $\left(850-1000 \mathrm{~mW} / \mathrm{cm}^{2}\right.$ output) for 40 seconds (for N-Fill) and 20 seconds for (Ionolux) according to the manufacturer's instructions.After fabrication, specimens were kept individually in artificial saliva in light proof containers and stored at $37^{\circ} \mathrm{C}$ for 24 hours to ensure complete polymerization ${ }^{[17]}$.

\section{Staining procedure}

$\mathrm{Tea}^{* * *}$ and cola*** staining media were used. The tea solution was prepared by immersing 5 pre-packaged doses of tea powder into $500 \mathrm{~mL}$ of boiling distilled water for 10 minutes ${ }^{[18]}$. The temperature of both staining media was adjusted at $37^{\circ} \mathrm{C}$ verified with a digital thermometer and kept in an incubator at $37^{\circ} \mathrm{C}^{[19]}$. Before staining a water resistant clear nail polish was used to cover the specimens completely except one surface to be subjected to stain. All specimens were immersed individually for 10 minutes in each staining medium twice daily with 5 hours intervals in light proof containers over a period of 30 days representing 10 hours exposure to a combined effect of the staining media. Between immersions specimens were individually kept in artificial saliva in the light proof containers at $37^{\circ} \mathrm{C}$ in an incubator throughout the period of the study ${ }^{[18]}$.

\section{Stain removal procedures}

Specimens were fixed in a specially prepared holder to facilitate the stain removal procedure.

In group IA and IIA: The stained surface of the specimens was polished using the Sof-Lex system, medium, Fine, and Super Fine polishing disks with a slow-speed handpiece ${ }^{* * * * * *}$ rotating in one direction for 30 seconds each according to manufacturer's instructions. The specimens were rinsed with distilled water after each step ${ }^{[9]}$. While, in group IB and IIB: The stained surface was treated with “ Opalesscence Boost" (40\% hydrogen peroxide) in-office bleaching gel as recommended by the manufacturer's instructions where the activator was mixed with the bleaching agent then the mixed gel was applied to the top surfaces of the specimens for two times, 20 minutes. After the final application was completed and all visible gel was removed, all the top surfaces were cleaned using distilled water.

\section{Color measurements}

Color of specimens was measured with a spectrophotometer (VITA Easyshade Advance).****** All measurements were made on a white plexiglass background in order to eliminate background light. The device was calibrated according to the

\footnotetext{
* Mylar strips, 0.005 mm; Odus Dental, Dietikon, Switzerland.

** LED H woodpecker, Guilin Woodpecker Medical Instrument Co.Ltd. China

*** Lipton, yellow table tea. Unilever, ARE, Alexandria.

**** Coca Cola. Egypt, Nasr City, Cairo, Egypt Beverage Industry Cairo

***** Micro motor strong series saeshin precision co., LTD. Power strong Dalseong-gun, Daegu, korea.

****** VITA Easyshade Advance, VITA Zahn- fabrik, Bad Säckingen, Germany.
} 
manufacturer's instructions. The measurement mode was selected and the probe tip was placed perpendicular in the center of the specimen flush to the surface to make accurate measurements ${ }^{[20]}$. Three consecutive measurements were made for each specimen and the instrument automatically averaged the three readings which were used for overall data analysis ${ }^{[21]}$.

Color parameters labeled $\left(L^{*}, a^{*}, b^{*}\right)$ were recorded where; $\mathrm{L}^{*}=$ lightness parameter and its value ranges from 0 for perfect black to 100 for perfect white, $a^{*}=$ red-green color parameter and $\mathrm{b}^{*}=$ yellow-blue color parameter ${ }^{[22]}$ and the mean color values were calculated.

\section{Color change calculation}

The color change values $\left(\Delta \mathrm{L}^{*}, \Delta \mathrm{a}^{*}, \Delta \mathrm{b}^{*}\right)$ were calculated by the subtraction method to detect the color change after the different steps of the study.

The total color change (color difference) is presented as $\Delta \mathrm{E}^{*}$ value which is more meaningful single value represents quantitative differences between $\mathrm{L}^{*}, \mathrm{a}^{*}$, and $\mathrm{b}^{*}$ values of specimens before and after the test.

It was calculated following staining, polishing and bleaching by the following equation:

$\Delta \mathrm{E}^{*}=\left[\left(\Delta \mathrm{L}^{*}\right)^{2}+\left(\Delta \mathrm{a}^{*}\right)^{2}+\left(\Delta \mathrm{b}^{*}\right)^{2}\right]^{1 / 2}$ where;

- $\Delta \mathrm{E}^{*}{ }_{2-1}=$ Color difference due to staining.

- $\Delta \mathrm{E}_{3-2}^{*}=$ Color difference after polishing procedure to remove stain.

- $\Delta \mathrm{E}_{4-2}^{*}=$ Color difference after bleaching procedure to remove stain.

- $\Delta \mathrm{E}^{*}{ }_{3-1}=$ Color difference after polishing compared to original base line.

- $\Delta \mathrm{E}_{4-1}^{*}=$ Color difference after bleaching compared to original base line.

$\Delta \mathrm{E}^{*}$ value $>3.3$ is clinically perceptible while the reported clinically acceptable values are in range of $(2.72-6.8)^{[23-26]}$.

\section{Statistical analysis}

Data were collected, tabulated, and statistically analyzed by software SPSS version 20; descriptive statistics were shown as Means \pm SD. One-way ANOVA test and standard student $\mathrm{t}$ - test at a level of significance $(\mathrm{P} \leq 0.05)$ were used to compare the recorded color difference values of both tested materials.

\section{RESULTS}

The statistical comparison between the mean color difference values $\left(\Delta \mathrm{E}^{*}\right)$ in each group is illustrated in table 1.

In Group I: One-way ANOVA recorded a highly statistically significant difference among $\Delta E^{*}$ values recorded throughout the steps of the study. Student t-test revealed a highly statistical significant difference between the recorded $\Delta \mathrm{E}^{*}$ value after staining versus that recorded either after polishing or bleaching denoting a significant effect of both tested methods utilized to remove stain of the tested nanohybrid composite resin, while a nearly similar effect of polishing and bleaching to remove stain was found with no significant difference between both.

It was also found that the color difference value compared to original base line value after polishing was not significant from that recorded after bleaching denoting nearly similar effect of bleaching and polishing on the tested composite resin.

Similarly, in Group (II): a highly statistically significant difference was found among all $\Delta \mathrm{E}^{*}$ values recorded throughout the study. However, Student t-test revealed that, the statistical difference between $\Delta \mathrm{E}^{*}$ value versus that recorded after staining was not significant, while a highly statistically significant color difference was found after bleaching compared to that recorded of the stained specimens. 
In addition, the statistical difference between color difference after polishing versus that recorded after bleaching was significant. Furthermore, color difference values compared to original base line after polishing and bleaching was significant denoting that bleaching significantly altered the color of tested resin-modified glass ionomer than polishing.

Additionally, the statistical comparison of color difference values $\left(\Delta \mathrm{E}^{*}\right)$ between both materials throughout the study is illustrated in table 2 .
After staining, both materials showed a significant perceptible color difference $\left(\Delta \mathrm{E}^{*}>3.3\right)$ however in group I, (N-Fill) the recorded $\Delta \mathrm{E}^{*}{ }_{2-1}$ was in the clinically acceptable range (2.72 - 6.8) while in group II (Ionolux) higher $\Delta \mathrm{E}^{*}{ }_{2-1}$ value was recorded that was beyond that clinically acceptable range. T-test revealed a highly statistically significant difference between both groups denoting high susceptibility of Ionolux to staining compared to N-Fill.

TABLE (1) Means \pm SD and statistical comparison between color difference values $\left(\Delta \mathrm{E}^{*}\right)$ of the test procedures in both tested materials.

\begin{tabular}{|c|c|c|c|c|}
\hline \multirow{2}{*}{ Color difference $\Delta \mathrm{E}^{*}$} & \multicolumn{2}{|c|}{$\begin{array}{c}\text { Group (I) } \\
\left(\mathrm{N}-\text { Fill) } \Delta \mathrm{E}^{*}\right.\end{array}$} & \multicolumn{2}{|c|}{$\begin{array}{c}\text { Group (II) } \\
\text { (Ionolux) } \Delta \mathrm{E}^{*}\end{array}$} \\
\hline & \multicolumn{2}{|c|}{ Mean \pm SD } & \multicolumn{2}{|c|}{ Mean $\pm \mathrm{SD}$} \\
\hline Staining to original baseline value $\left(\Delta \mathrm{E}^{*}{ }_{2-1}\right)$ & \multicolumn{2}{|c|}{$4.37 \pm 3.29$} & \multicolumn{2}{|c|}{$7.59 \pm 4.61$} \\
\hline Polishing to stain value $\left(\Delta \mathrm{E}_{3-2}^{*}\right)$ & \multicolumn{2}{|c|}{$19.05 \pm 6.41$} & \multicolumn{2}{|c|}{$10.07 \pm 6.87$} \\
\hline Bleaching to stain value $\left(\Delta \mathrm{E}_{4-2}^{*}\right)$ & \multicolumn{2}{|c|}{$19.64 \pm 7.46$} & \multicolumn{2}{|c|}{$15.7 \pm 4.27$} \\
\hline Polishing to original baseline value $\left(\Delta \mathrm{E}_{3-1}^{*}\right)$ & \multicolumn{2}{|c|}{$18.56 \pm 6.9$} & \multicolumn{2}{|c|}{$10.02 \pm 4.05$} \\
\hline Bleaching to original baseline value $\left(\Delta \mathrm{E}^{*}{ }_{4-1}\right)$ & \multicolumn{2}{|c|}{$15.9 \pm 6.28$} & \multicolumn{2}{|c|}{$15.83 \pm 2.56$} \\
\hline (Among all $\Delta \mathrm{E}^{*}$ values) F. test & $\mathrm{F}=6.438$ & $\mathrm{P}=0.001 * *$ & $\mathrm{~F}=4.084$ & $\mathrm{P}=0.001 * *$ \\
\hline$\left(\Delta \mathrm{E}^{*}{ }_{3-2}\right)$ vs $\left(\Delta \mathrm{E}^{*}{ }_{2-1}\right) \mathrm{T}$. test & $\mathrm{T}=8.362$ & $\mathrm{P}=0.001 * *$ & $\mathrm{~T}=1.302$ & $P=0.202$ \\
\hline$\left(\Delta \mathrm{E}^{*}{ }_{4-2}\right)$ vs $\left(\Delta \mathrm{E}^{*}{ }_{2-1}\right) \mathrm{T}$. test & $\mathrm{T}=7.853$ & $\mathrm{P}=0.001 * *$ & $\mathrm{~T}=4.932$ & $\mathrm{P}=0.001 * *$ \\
\hline$\left(\Delta \mathrm{E}_{4-2}^{*}\right)$ vs $\left(\Delta \mathrm{E}_{3-2}^{*}\right) \mathrm{T}$. test & $\mathrm{T}=0.193$ & $\mathrm{P}=0.852$ & $\mathrm{~T}=2.970$ & $\mathrm{P}=0.008 * *$ \\
\hline$\left(\Delta \mathrm{E}_{3-1}^{*}{ }_{3-1}\right)$ vs $\left(\Delta \mathrm{E}^{*}{ }_{4-1}\right) \mathrm{T}$. test & $\mathrm{T}=0.904$ & $P=0.379$ & $\mathrm{~T}=3.832$ & $\mathrm{P}=0.001 * *$ \\
\hline
\end{tabular}

TABLE (2) Means \pm SD and statistical comparison between color difference values $\left(\Delta \mathrm{E}^{*}\right)$ in both tested materials.

\begin{tabular}{|l|c|c|c|c|}
\hline \multirow{2}{*}{ Color difference $\Delta \mathrm{E}^{*}$} & $\begin{array}{c}\text { Group }(\mathrm{I}) \\
\text { G-Fill } \Delta \mathrm{E}^{*}\end{array}$ & $\begin{array}{c}\text { Group (II) } \\
\text { (Ionolux) } \Delta \mathrm{E}^{*}\end{array}$ & \multicolumn{2}{c|}{$\begin{array}{c}\mathrm{T} \text { test } \\
\text { (p value) }\end{array}$} \\
\cline { 2 - 5 } & Mean $\pm \mathrm{SD}$ & Mean $\pm \mathrm{SD}$ & \multicolumn{2}{|c|}{$\mathrm{I}$ vs II } \\
\hline Staining to original baseline value $\left(\Delta \mathrm{E}^{*}{ }_{2-1}\right)$ & $4.37 \pm 3.29$ & $7.59 \pm 4.61$ & $\mathrm{~T}=3.114$ & $\mathrm{P}=0.003^{* *}$ \\
\hline Polishing to stain value $\left(\Delta \mathrm{E}_{3-2}^{*}\right)$ & $19.05 \pm 6.41$ & $10.07 \pm 6.87$ & $\mathrm{~T}=3.022$ & $\mathrm{P}=0.007 * *$ \\
\hline Bleaching to stain value $\left(\Delta \mathrm{E}_{4-2}^{*}\right)$ & $19.64 \pm 7.46$ & $15.7 \pm 4.27$ & $\mathrm{~T}=1.431$ & $\mathrm{P}=0.169$ \\
\hline Polishing to original baseline value $\left(\Delta \mathrm{E}^{*}{ }_{3-1}\right)$ & $18.56 \pm 6.9$ & $10.02 \pm 4.05$ & $\mathrm{~T}=3.384$ & $\mathrm{P}=0.003 * *$ \\
\hline Bleaching to original baseline value $\left(\Delta \mathrm{E}^{*}{ }_{4-1}\right)$ & $15.9 \pm 6.28$ & $15.83 \pm 2.56$ & $\mathrm{~T}=0.034$ & $\mathrm{P}=0.974$ \\
\hline
\end{tabular}


Regarding the effect of polishing on stain removal, clinically unacceptable $\Delta \mathrm{E}^{*}{ }_{3-2}$ values were detected in both groups with high significant difference.

Similar findings were found regarding the effect of bleaching on stain removal recording clinically unacceptable $\Delta \mathrm{E}^{*}{ }_{4-2}$ values in both groups, with no statistically significant difference.

Furthermore, all color difference values compared to the original baseline were perceptible denoting a significant lightening of color.

T-test revealed a highly statistical significant difference between $\Delta \mathrm{E}^{*}{ }_{3-1}$ value recorded after polishing in group I versus that recorded in group II denoting a significant effect of polishing on the tested nanohybrid composite resin than resin modified glass ionomer.

On the other hand, the effect of bleaching provided nearly similar effect on the tested nanohybrid composite and resin modified glass ionomer with no statistically significant difference between both.

\section{DISCUSSION}

The choice of the right restorative material may provide more pleasing, long lasting results for the patient and the practitioner, since the expectation for the dental restoration is to be ideal and undetectable to others upon visual inspection ${ }^{[27]}$. It must not only provide an initial shade match, but also maintain an esthetic appearance over the years.

It should be highlighted that the consumption of beverages is highly popular and the inhibition of its ingestion for esthetical purposes is impracticable to most of the population ${ }^{[28]}$. Since the external and the surface types of discolorations are closely related to hygiene, dietary, and smoking habits ${ }^{[29]}$, so the maintenance of the esthetics of a restoration is therefore related to the patients' habits and lifestyle ${ }^{[16]}$.
$\mathrm{N}$-Fill composite resin chosen in this study is a nanohybrid type that was claimed by manufacturer that its hydrophobic effect may reduce the staining intake ${ }^{[30]}$ while Ionolux (resin modified glass ionomer) was reported to have an outstanding esthetics ${ }^{[31]}$.

The specimens were fabricated in close contact with a Mylar strip and a glass slide to spontaneously and consistently produce a smooth surface, thus abolishing any need for polishing ${ }^{[32]}$. The curing light was held in contact with the surface, hence establishing uniformity in the depth of cure. In this way, some of the potential risk factors for color instability were eliminated. In addition, A2 shade was standardized in both tested materials to minimize the effect of shade variation ${ }^{[33]}$.

The staining method used in this study aimed to mimic a real life situation, where the staining solutions were maintained at $37^{\circ} \mathrm{C}$ to simulate the oral cavity temperature and hence eliminate any alterations in their properties or potency due to temperature variations. In addition, the tested effect of these solutions was combined as in usual consumption by most people. For the remaining part of the day the specimens were kept in artificial saliva to mimic its neutralizing effect in the mouth. Before staining, two layers of nail polish were applied to cover the specimens completely except one surface subjected to stain to provide an impermeable barrier to the staining solutions in a trial to simulate the clinical situation ${ }^{[34]}$.

The VITA Easy-shade spectrophotometer used in this study was reported by Kim-Pusateri et al ${ }^{[35]}$ to provide both reliability and accuracy values greater than $90 \%$. Color change of restorative dental materials measured with a spectrophotometer using CIE L*a*b* color system is commonly used in dentistry because $\mathrm{L}^{*}, \mathrm{a}^{*}$, and $\mathrm{b}^{*}$ are evenly distributed in a perceptual color space ${ }^{[36]}$. In addition to have the advantage of being repeatable, sensitive, objective, universally accepted, and can measure small color differences. 
The valid acceptability and perceptibility tolerances for shade mismatch in a clinical study using spectroradiometric instrumentation was determined by Douglas et al ${ }^{[37]}$ reporting that the predicted color difference at which $50 \%$ of the dentist observers could perceive was $2.6 \Delta \mathrm{E}^{*}$ units, whereas, the predicted color difference at which $50 \%$ of the subjects would remake the restoration due to color mismatch was $5.5 \Delta \mathrm{E}^{*}$ units. However it was recently reported in different studies ${ }^{[23-26]}$ that $\Delta \mathrm{E}^{*}$ values of 2.72 to 6.8 are acceptable for dental restorations.

In general, the current results revealed a variation between both tested restorative materials regarding their susceptibility to staining with food colorants and their amenability to stain removing methods which came in agreement with Al-Nahedh and Awliya ${ }^{[9]}$.

Currently, it was found that, both tested materials were discolored after subjected to a combined effect of staining with tea and cola solutions and both showed a clinically perceptible total color changes recording $\Delta \mathrm{E}^{*}>3.3$. However, the color difference for nanohybrid composite resin could be considered clinically acceptable and may not require replacement according to different studies ${ }^{[23-26]}$. While a $\Delta \mathrm{E}^{*}$ value recorded for tested RMGI (Ionolux) denoted that, color change was clinically detectable and require replacement.

The observed staining could be partly related to the method of specimen fabrication, where they were cured directly in contact with Mylar strip, although provide smooth surface. However, the organic matrix-rich surface layer tend to stain by adsorption and absorption of the colorants due to their higher resin content resulting more staining than polished surfaces that could be stained only due to adsorption of colorants to the roughly arranged exposed fillers ${ }^{[9,38]}$.

The discoloration was proved to involve stain adsorption and subsurface absorption. It was proposed by Bagheri et al ${ }^{[39]}$ that resin polymers and dietary colorants have different polarities. So, materials with a resin matrix polarity compatible with that of yellow colorants may facilitate its absorption into the organic phase of the material. Also, Lee YK et al ${ }^{[40]}$ ascribed the discoloration of the subsurface absorption to chemical reactions related to denaturing factors that cause stable discoloration in black tea and tannin-containing compounds. Furthermore, Yazici et al ${ }^{[41]}$ reported that this type of discoloration may occur due to penetration of yellow pigments through microcracks or interfacial gaps at the interface between filler and matrix.

Regarding the effect of cola, Zajkani et al ${ }^{[42]}$ reported that, it is a yellow-brown carbonated beverage, in addition to its decolorizing effect, it has an erosive impact on resin materials. Its low $\mathrm{pH}$ due to the presence of orthophosphoric and carbonic acids can result in discoloration and staining of resin based restoration. Also, the caramel color in cola solution causes color changes ranging from palest yellow to deepest brown. ${ }^{37}$ However, it was reported by others ${ }^{[43,44]}$ that, cola drink does not appear to be strongly implicated in color change of composites, despite the presence of phosphoric acid. In addition, the presence of phosphate ions in cola may suppress the dissolution since they have been shown to reduce the dissolution rate of calcium phosphate from the tooth.

Regarding the effect of cola on resin modified glass ionomer; the subsurface discoloration could be attributed to $\mathrm{H}+$ ions diffused into its components replacing the metal cations in the matrix which diffuse outwards and are released from the surface. Accordingly more cations would be extracted from the surrounding glass particles, causing them to dissolve. With time, the material presents a roughened surface with voids and protruded, undissolved glass particle resulting in greater water and food colorant absorption ${ }^{[45]}$. 
It has been established by Kugel ${ }^{[46]}$ and Moszner et al ${ }^{[47]}$ that, the resin matrix of resin-based restorative materials plays an important role in stain susceptibility, influencing color stability due to their hydrophobic or hydrophilic monomers. In general, hydrophobic materials such as resin composites showed greater color stability and stain resistance than the hydrophilic materials such as resinmodified glass ionomers ${ }^{[8]}$ which, supported the current findings where, the tested N-Fill nanohybrid composite resin resulted in less staining compared to the tested RMGI and was explained by the hydrophilic nature of 2-hydroxyethyl methacrylate (HEMA) present in its liquid.

Furthermore, it was reported by Catelan et al ${ }^{[48]}$ that, water acts as a carrier for staining agents in the water sorption process. Excessive water sorption was proved to expand and plasticize the resin component, hydrolyzing the silane and causing micro cracks or interfacial gaps between filler and matrix allowing stain penetration and discoloration ${ }^{[186]}$. So, the less susceptibility of the tested nanohybrid composite resin to staining could be also attributed to its low water uptake.

On the other hand, Anstice and Nicholson [49] suggested that, resin-modified glass ionomers have the potential to uptake water from the environment while others, Mathis and Ferracane ${ }^{[188]}$ have found that the resin network reduces the diffusion of water into the material. So, the degree of water sorption is product-dependent and appears to be influenced by the resin (HEMA) content which can take up large amounts of water, possibly up to $80 \%$ by mass. Materials with higher resin (HEMA) content [Ionolux contains 25-50\%] are therefore expected to absorb more water.

Likewise, the filler content was reported to play an important role in composite resin color stability. Currently, N-Fill has high volume of inorganic fillers ( $>82 \%$ by weight and $67 \%$ by volume) thus reducing the resin volume which improves color stability. These findings came in agreement with
Yazici et al ${ }^{[41]}$ concluding that the composites with the lowest filler contents had poor color stability. On the other hand, Sarafianou et al ${ }^{[50]}$ reported that, the composite resins containing higher volume of filler decreases the degree of polymerization and so could be more susceptible to discoloration which came in disagreement with the current results.

Once staining occurs, several ways were reported to remove superficial stains from resin-based restorations including tooth brushing, repolishing, and bleaching. In the current study it was preferred to use more rapid methods to remove the stains following those reported by Turkun and Turkun ${ }^{[12]}$.

Regarding the effect of polishing on color difference of both tested materials, there was a detectable effect of polishing on color difference in N-Fill than Ionolux and this may be attributed according to Al-Nahedh and Awliya ${ }^{[9]}$ to breakdown of the aggregated fillers to their primary nanofillers in composite specimens during polishing procedure. Therefore, successful removal of the surface layer responsible for the stain was achieved.

Color difference between polished specimens and original color values revealed more effect of polishing on the tested nanohybrid composite which may be related to the degree and its method of stain (adsorption only) while, RMGI is stained by both adsorption and subsurface absorption and revealed higher degree of stain.

Bleaching gels (whether carbamide or hydrogen peroxide) were reported to lighten resin based materials. This is however is largely dependent on the type of the stain, composition of the material and duration of the bleaching application ${ }^{[51]}$. The mechanism of stain removal by the bleaching agents is different from that by the Sof-lex disks which work by abrading the surface. Peroxide decomposes into free radicals that attack the organic molecules releasing other radicals. These radicals which oxidize and breakdown large pigmented molecules responsible for color stain into smaller less pigmented and less visible molecules through 
oxidation and reduction reaction and this might explained the superior effect of bleaching gel on composite specimens immersed in tea ${ }^{[9,52]}$. It was also reported that oxidation of the pigments may occur as a result of direct interaction with hydrogen peroxide on the resin surface inducing oxidative cleavage of polymer chains; therefore, any unreacted double bonds are expected to be the most vulnerable parts of the polymers. Furthermore, free radicals induced by peroxides may impact the resin filler interface and cause filler-matrix debonding forming microscopic cracks, resulting in surface roughness leading to diffusion of the bleaching agent that was reported to demonstrate an extensive ability for diffusion.

Currently, the tested in-office bleaching procedure was efficient in removing stains from both materials that were beyond the clinically acceptable range with more lightening effect of N-Fill than Ionolux which came in agreement with Abd Alhadi et al ${ }^{[53]}$ attributing this effect to the Dimethacylates with higher filler content (82-83\%wt.) that may be less resistant to the bleaching agent and ${ }^{[54]}$ who attributed this to existing interstitial porosities within the clusters of N-Fill could act as pathways allowing the peroxide and the produced radicals to penetrate through and to interact with the internal structure of composite resin material. Furthermore, the recorded lighter color came in agreement with different studies ${ }^{[9,55]}$ reporting that all stained tooth colored restorative materials demonstrated a tendency to become lighter and ascribed this to the effect of bleaching agents on resin matrix that may be easily degraded.

While the effect of bleaching on RMGI restorative materials may be explained by chemical softening due to erosion of matrix, wash off and release of metal cations from the surface. If the polymerization reaction results in low conversion rates, the bleaching material may react with unconverted $\mathrm{C}=\mathrm{C}$ bonds of the monomer matrix system. In particular, traces of metals such as iron or copper, accelerating the decomposition to hydroxyl radicals, result in an enhanced efficacy of $\mathrm{H}_{2} \mathrm{O}_{2}{ }^{[55]}$.

The currently observed clinically unacceptable color lightening of both materials, could be related to the higher percentage of bleaching agent (40\% hydrogen peroxide) when compared to others utilized lower ${ }^{[56,57]}$, while Meireles et al ${ }^{[96]}$ found that, the lower carbamide peroxide concentrations were more effective than higher concentrations, reporting that contact time of bleaching agent maybe more important factor than the concentration of bleaching agents.

However, the current result came in disagreement with Turkun and Turkun ${ }^{[12]}$ who reported that discoloration of the resin veneers and composite resin restorations can be partially removed by inoffice bleaching and repolishing procedures and this may be attributed to the difference of the material and methodology utilized in their studies.

It is worth to emphasize the impossibility of establishing an exact correlation between the in vitro and in vivo tests, since the oral environment cannot be reproduced and restorative materials are never subjected to staining media for such period utilized in the laboratory. However, the current results can only give an insight into how different resin-based materials may behave when exposed to such beverages, thus affecting the clinician's choice of material and the patient's control of dietary habits, so it could provide clinically useful information about the staining potential of the materials used and efficiency of a common polishing and bleaching procedures for stain removal ${ }^{[9]}$.

\section{CONCLUSIONS}

Under the conditions of this in vitro study, the following could be concluded:

The tested polishing and bleaching procedures utilized to remove stain from both tested materials resulted in a significant color change that was beyond the clinically accepted range. 


\section{RECOMMENDATIONS}

Further studies considering the color matching between tooth enamel and different resin-based restoration following staining removal procedures would be beneficial.

\section{REFERENCES}

1- Mehrotra V, Sawhny A, Gupta I, Gupta R. Tell Tale Shades Of Discolored teeth. A Review. Indian J Dent Sci 2014;6: 95-99.

2- Padiyar N, Kaurani P. Color stability: An important physical property of esthetic restorative materials. IJCDS 2010;1: 81-84.

3- Attin T, Hannig C, Wiegand A, and Attin R. Effect of bleaching on restorative materials and restorations. A systemic review. Dent Mater J 2004;20: 852-861.

4- Ferracane JL. Current trends in dental composites. Crit Rev Oral Biol Med 1995;6: 302-318.

5- Ferracane JL. Resin composite--state of the art. Dent Mater J 2010;27: 29-38.

6 - Craig RG, Powers JM, Wataha JC. Dental materials properties and manipulation. 7th edition. St Louis: Mosby; 2000 .

7- Wilson AD. Developments in glass-ionomer cements. Int J Prosthodont 1989;2: 438-446.

8- Iazetti G, Burgess JO, Gardiner D, Ripps A. Color stability of fluoride containing restorative materials. Oper Dent 2000;25: 520-525.

9- Al-Nahedh H, Awliya W. The effectiveness of four methods for stain removal from direct resin-based composite restorative materials. Saudi Dent J 2013;25: 61-67.

10- Ren Y, Feng L, Serban D, Malmstrom S.H. Effects of common beverage colorants on color stability of dental composite resins: The utility of a thermocycling stain challenge model in vitro. J Dent 2012;40: 48-56.

11- Azarpazhooh A, Limeback H. The application of ozone in dentistry: a systematic review of literature. J Dent 2008;36: 104-116.

12- Turkun LS, Turkun M. Effect of Bleaching and Repolishing Procedures on Coffee and Tea Stain Removal from Three Anterior Composite Veneering Materials. J Esthet Rest Dent 2004;16: 290-301.
13- Kugel G, Kastali S. Tooth whitening efficacy and safety: a randomized and controlled clinical trial. Compend Contin Educ Dent 2000;29: 516-521.

14- Dahl JE. Tooth bleaching - a critical review of the biological aspects. Crit Rev Oral Biol Med 2003;14: 292-304.

15- Meireles SS, Demarco FF, Santos Ida S, Damith SC, Della Bona A. Validation and reliability of visual assessment with a shade guide for tooth color classification. Oper Dent 2008;33: 121-126.

16- Poggio C, Beltrami R, Scribante A, Colombo M, Chiesa M. Surface discoloration of composite resins: Effects of staining and bleaching. J Dent Res 2012;9: 567-573.

17- Lepri PC, Palma GR. Surface roughness and color change of a composite: Influence of beverages and brushing. Dent Mater 2012;31: 689-696.

18- Al kheraif A, Bin qasim S, Ramakrishnaiah R, Rehman I. Effect of different beverages on the color stability and degree of conversion of nano and microhybrid composites. Dent Mater 2013;32: 326-331.

19- Tuncer D, Karaman E, Firat E. Does the temperature of beverages affect the surface roughness, hardness, and color stability of a composite resin? Euro J Dent 2013; 7: 165-171.

20- Ergücü Z, Türkün LS, Aladag A. Color Stability of Nanocomposites Polished with One-Step Systems. Oper Dent 2008;33: 413-420.

21- Fontes TS, Fernández RM, De moura MC, Meireles SS Color stability of a nanofill composite: effect of different immersion media. J Appl Oral Sci 2009; 175:388-391.

22- Sikri VK. Color: Implications in dentistry. J Conserv Dent 2010;13: 249-255.

23- Zimmerli B, Koch T, Flury S, Lussi A. The influence of toothbrushing and coffee staining on different composite surface coatings. Clin Oral Invest 2012;16: 469-479.

24- Johnston WM, Kao EC. Assessment of appearance match by visual observation and clinical colorimetry. J Dent Res 1989;68: 819-822.

25- Ruyter IE, Nilner K, Moller B .Color stability of dental composite resin materials for crown and bridge veneers. Dent Mater 1987;3: 246-251.

26- Ragain JC, Johnston WM. Color acceptance of direct dental restorative materials by human observers. Color Res Appl 2000;25: 278-285. 
27- Mohan M, Shey Z, Vaidyanathan J, Vaidyanathan TK, Munisamy S, Janal M. Color changes of restorative materials exposed in vitro to cola beverage. J Pediatr Dent 2008;30: 309-316.

28- Téo TB, Takahashi MK, Gonzaga CC, Lopes MGK. Avaliação, após clareamento, da alteração de cor de dentes bovinos imersos em soluções com elevado potencial de pigmentação. RSBO 2010;7: 401-405.

29- Gupta G, Gupta T. Evaluation of the effect of various beverages and food material on the color stability of provisional materials. An in vitro study; J Conserv Dent 2011;14: 287-292.

30- MEGADENTA Dentalprodukte GmbH. Dental program. Web:info@megadenta.de.E-Mail: www.megadenta.de.

31- Glass ionomer materials Product overview. Web:info@ voco.com. E-Mail: www.voco.com.

32- Attar N. The Effect of Finishing and Polishing Procedures on the Surface Roughness of Composite Resin Materials. J Contemp Dent Prac 2007;8: 27-35.

33- Irawan AB, Irawan NS, Masudi SM, Sukminingrum N, Alam MK. 3D Surface Profile and Color Stability of Tooth Colored Filling Materials after Bleaching. Biomed Res Int 2014;1:1-9.

34- Valentini F, Oliveira SG, Guimarães GZ, Barbosa RP, Moraes RR. Effect of surface sealant on the color stability of composite resin restorations. Braz Dent J 2011; 22: $365-368$.

35- Kim-Pusateri, Brewer JD, Davis EL, Wee AG. Reliability and Accuracy of Four Dental Shade-matching devices. J Prosthet Dent 2009;101: 193-199.

36- Nuaimi HO, Ragab HM. Effect of aggressive beverage on the color stability of different nano-hybrid resin based composite. Eur J Gen Dent 2014;3: 190-193.

37- Douglas RD, Brewer JD. Acceptability of shade differences in metal ceramic crowns. J Prosthet Dent 1998;79: 254-260.

38- Paravina RD, Roeder L, Lu H, Vogel K, Powers JM. Effect of finishing and polishing procedures on surface roughness, gloss and color of resin-based composites. Am J Dent 2004;17: 262-266.

39- Bagheri R, Burrow M. F, Tyas M. Influence of FoodSimulating Solutions and Surface Finish on Susceptibility to Staining of Aesthetic Restorative Materials. J Dent 2005;33: 389-398.
40- Lee YK, Lim BS, Rhee SH. Changes in scattering and absorption properties of esthetic filling materials after aging. J Biomed Mater Res B Appl Biomater 2007;80: 131-139.

41- Yazici AR, Celik C, Dayangaç B and Ozgünaltay G. The effect of curing units and staining solutions on the color stability of resin composites. Oper Dent 2007;32: 616-622.

42- Zajkani E, Abdoh Tabrizi M, Ghasemi A, Torabzade H, Kharazifard MJ. Effect of Staining Solutions and Repolishing on Composite Resin Color Change. JIDAI 2013;25: 83-90.

43 - Mundim FM, Garcia Lda F, Pires-de-Souza Fde C. Effect of staining solutions and repolishing on color stability of direct composites. J Appl Oral Sci 2011;18: 249-254.

44- Aliping-McKenzie M, Linden RW, Nicholson JW. The effect of Coca-Cola and fruit juices on the surface hardness of glassionomers and “compomers". J Oral Rehabil 2004; 31: 1046-1052.

45- Bajwa NK and Pathak A. Change in Surface Roughness of Esthetic Restorative Materials after Exposure to Different Immersion Regimes in a Cola Drink. ISRN Dent Vol 2014, Article ID 353926, 6.

46- Kugel G. Direct and indirect adhesive restorative materials: a review. Am J Dent 2000;13: 35-40.

47- Moszner N, Fischer U.K, Angermann J, Rheinberger V. A partially aromatic urethane dimethacrylate as a new substitute for Bis-GMA in restorative composites. Dent Mater 2008;24: 694-699.

48- Catelan A, Briso ALF, Sundfeld RH, Goiato MC, dos Santos PH. Color stability of sealed composite resin restorative materials after ultraviolet artificial aging and immersion in staining solutions. J Prosthet Dent 2011;105: 236-241.

49- Anstice HM, Nicholson JW. Studies on the structure of light-cured Glass-ionomer cements. Materials in Medicine. J Mat Sci 1992;3: 447-451.

50- Sarafianou A, Iosifidou S, Papadopoulos T, Eliades G. Color Stability and Degree of Cure of Direct Composite Restoratives after Accelerated Aging. Oper Dent 2007;32: 406- 411 .

51- Villalta P, Lu H, Okte Z, Garcia-Godoy F, Powers JM. Effects of staining and bleaching on color change of dental composite resins. J Prosthet Dent 2006;95: 137-142. 
52- Flaitz CM, Hicks MJ. Effects of carbamide peroxide whitening agents on enamel surfaces and caries-like lesion formaltion: an SEM and polarized light microscopy in vitro study. J Dent Child 1996;63: 249-256.

53- Abd Alhadi N, Kadhim AJ, Jabbar AM. Effect of 38\% hydrogen peroxide agent on color change of composite resins stained with tea and coffee beverages (An in vitro study). MDJ 2012;9: 149-158.

54- Waly GH, El Sharkawy FM. Hydrogen peroxide bleaching: Effects on surface roughness, color and staining susceptibility of microhybrid and nanocomposite. J Am Sci 2012;8: 190-199.
55- Ayad NM. The effect of a current home bleaching agent on the color of nine tooth colored restorative materials stained with common beverages (an in vitro study). IJDS 2009; 6: $1937-8238$.

56- Yousef M, Abo El Naga A. Color Stability Of Different Restoratives After Exposure To Coloring Agents. J Am Sci 2012;8: 20-26.

57-Anagnostou M, Chelioti G, Chioti S, Kakaboura A. Effect of tooth-bleaching methods on gloss and color of resin composites. J Dent 2010;38: 129-136. 